\title{
From Otto Neurath's Isotype to Multiple Worlds of Visual Media
}

Karl H. Müller \& Armin Reautschnig, Vienna

The starting and the reference point for this article lies in Otto Neurath's Isotype (International System of Typographic Pictorial Education) which was developed as an international picture language from the late 1920s onwards up to Neurath's untimely death in 1945. Even eighty years after its rapid construction phase, Isotype remains a huge source for inspirations and a reference point for promoting visualization in a most comprehensive way, albeit within the restrictions and constraints of the technological settings of the 1920 s or 1930s. ${ }^{1}$

In the subsequent article, three major issues will be addressed. The first part provides an assessment of the relative importance of visualization in contemporary science and society and gives a preliminary answer to the question whether visualization should still be considered as an important scientific or societal topic. The second issue deals with rapid changes in information and communication technologies and a general drift towards a digital information and knowledge base. Within these great transformations the question will be answered whether Neurath's mode of Isotype-production should be adapted or accommodated to today's scientific or societal environments. Finally, the third topic deals with a relatively new visual medium which can be classified as visual data analysis (VDA). VDA is a new visual way for analyzing complex micro data sets in the social sciences within a comparative framework. 


\section{1}

\section{A New Kind of Visual Science}

The first major issue for this article lies in a preliminary assessment of the contemporary relevance of visualization in science on the one hand and in society on the other hand.

Turning to the first part of the question it is interesting to note for historical reasons that Otto Neurath's Isotype was viewed by his friends and colleagues from the Vienna Circle or from the Unified Science-movement as an interesting and stimulating way of communication which however was situated outside the domains of scientific analysis proper. Within science, visualizations in the form of Isotype-diagrams were mostly seen as illustrations without any cognitive surplus value. ${ }^{2}$

Several decades later the assessment of a marginal impact of visualization within the scientific domain has changed dramatically. Again for historical reasons it is intriguing to see that one of Otto Neurath's fiercest opponents in economic, societal or planning arenas, namely Friedrich August von Hayek, would have become his strongest ally in the field of visualization within scientific fields. In 1967, Friedrich August von Hayek wrote a rather neglected article entitled 'The Theory of Complex Phenomena' (Hayek, 1967) which was published several years later as a small booklet in German 'Die Theorie komplexer Phänomene' (Hayek, 1972, reprinted 1996). In this article, Hayek developed a typology of complex phenomena and processes which he clearly differentiated from their simple counterparts. Table 1 lists the results of Hayek's distinctions between simple and complex phenomena or processes across several dimensions. It turns out that Hayek's differentiations are almost identical to a more recent dualistic conceptualization of a phase transition from Science I, the science of theoretical physics and of relative simplicity to Science II, the science of the life sciences and of relative complexity ${ }^{3}$. Both Hayek's typology of simple and complex phenomena and the Science I-Science II-typology focus on patterns, pattern recognition and pattern formation as the core-elements of analysis. But a shift from laws to patterns, almost by necessity, implies that the role of visualization must have increased significantly.

According to Table 1 complexity science alias Science II proves to be pattern-based, and stands in a striking contrast to the law-based paradigm for simple phenomena and processes under Science I. 
Table 1 Friedrich August von Hayek's Main Distinctions between Simple (Science I) and Complex Phenomena (Science II)

\begin{tabular}{|c|c|c|}
\hline Dimensions & Simple Phenomena (Science I) & Complex Phenomena (Science II) \\
\hline $\begin{array}{l}\text { Degree of } \\
\text { Complexity }\end{array}$ & Low & High \\
\hline $\begin{array}{l}\text { Measure of } \\
\text { Complexity }\end{array}$ & $\begin{array}{l}\text { Small number of } \\
\text { Variables }\end{array}$ & $\begin{array}{l}\text { Large number of } \\
\text { Variables }\end{array}$ \\
\hline $\begin{array}{l}\text { Bonds between } \\
\text { Variables }\end{array}$ & Causal Relations & $\begin{array}{l}\text { Degree of } \\
\text { Complexity }\end{array}$ \\
\hline $\begin{array}{l}\text { Specification } \\
\text { Schema }\end{array}$ & Laws & Patterns \\
\hline $\begin{array}{l}\text { Mode of } \\
\text { Analysis }\end{array}$ & $\begin{array}{l}\text { Covering } \\
\text { Law-Model }\end{array}$ & $\begin{array}{l}\text { Pattern-Recognition and } \\
\text { Pattern Formation }\end{array}$ \\
\hline Forecasting & Law-based & Pattern-based \\
\hline Leading Science & Theoretical Physics & $\begin{array}{l}\text { Evolutionary Biology and } \\
\text { Complexity Sciences }\end{array}$ \\
\hline
\end{tabular}

As a consequence, it can be stated for the science domain in general that the importance of patterns and, thus, of visualizations has increased dramatically over the last decades and, in all probability, will continue to do so in the future. Visualization in science has moved from the cognitive margins and from a mere by-product of algorithmic analysis to the core mode of scientific investigations.

The growing importance of patterns and visualizations within the increasingly dominant life sciences and the sciences of complexity is accompanied by another series of shifts and phase transition that separate today's social science work environments and practices from Neurath's office and Isotypeenvironments in the 1930s or the early 1940s. Within the sciences in general and the social sciences in particular three major changes or phase transitions occurred during these decades simultaneously in the domains of epistemic cultures $^{4}$, laboratories ${ }^{5}$ and research infrastructures. In all three instances a profound shift occurred towards digital or cyber-contexts, manifesting themselves in digital or cyber-epistemic cultures, in digital or cyber-labs and in digital or cyber-research infrastructures. ${ }^{6}$ 
For the subsequent discussion it becomes of utmost importance that the daily routines of social scientists are more and more embedded in a digital or cyber-environment which, of course, has strong repercussions for traditional or analogue communication tools like Isotype as well.

\section{2 \\ Visual Media and Visual Settings}

Turning to the second part of the initial question, viz. the contemporary societal relevance of visualization, a few concepts need to be introduced, namely the notions of visual media and of visual settings. The concept of a medium will be used in a rather specific manner far from the current social science or humanities frameworks ${ }^{7}$ and it follows closely to a proposal by Douglas R. Hofstadter (1997) who defined a medium in the following way:

A medium is a vehicle for patterns, a propagator of distortions, a transmitter of disturbances. [...] A linguistic medium is a carrier of messages. (Hofstadter 1997: 181)

Hofstadter goes on to introduce the notion of linguistic media by specifying that

a linguistic medium is definable as: a language restricted by a set of constraints that are not so tight as to preclude the expression of arbitrary meanings (Hofstadter 1997: 182)

Thus, different languages can be seen as instances for a linguistic medium. One can easily see that in Hofstadter's understanding a medium, linguistic or otherwise, is very closely linked to notions like rule systems, production systems, grammars or programs.

In this spirit, a visual medium can be described as a visual configuration 'restricted by a set of constraints that are not so tight as to preclude' the formation or the recognition of arbitrary visual patterns. Thus, the notion of pattern formation and pattern recognition stands at the core of visual media. Additionally, rule or production systems, broadly conceived, for pattern formation or for pattern recognition can be understood as specific instances of visual media. 
Table 2 The New Multiplicity of Visual Media, Settings and Utilization Contexts

\begin{tabular}{|c|c|c|}
\hline $\begin{array}{c}\text { Societal Systems/ } \\
\text { Networks }\end{array}$ & $\begin{array}{l}\text { Visual Media } \\
\text { and Utilization Contexts }\end{array}$ & Visual Settings \\
\hline Education & $\begin{array}{c}\text { Visual Education and Visual } \\
\text { Learning in Primary, Second- } \\
\text { ary and } \\
\text { Tertiary Education }\end{array}$ & $\begin{array}{l}\text { Schools and } \\
\text { Institutions of Higher Education }\end{array}$ \\
\hline Science & $\begin{array}{c}\text { Complex Visual Analysis, Visual } \\
\text { Data-Mining and Exploratory } \\
\text { Visual Analysis, } \\
\text { Visual Languages for } \\
\text { Animal-Man Communication, etc. }\end{array}$ & Digital Science Labs \\
\hline Economy & Visual Occupational Learning & Work-Places \\
\hline $\begin{array}{l}\text { Information and } \\
\text { Communication }\end{array}$ & $\begin{array}{l}\text { Visual Modules in Newspapers, } \\
\text { Journals, Books, etc; Visual } \\
\text { Components } \\
\text { in User-Surfaces of Information } \\
\text { and } \\
\text { Communication Technologies } \\
\text { (ICT) }\end{array}$ & $\begin{array}{l}\text { Private Households; } \\
\text { Public Spaces, etc. }\end{array}$ \\
\hline Arts and Culture & Visual Artistic Media & $\begin{array}{c}\text { Museums, Exhibitions, } \\
\text { Art Galleries, Public Installations, } \\
\text { Cyber-Settings, etc. }\end{array}$ \\
\hline Life Worlds & $\begin{array}{l}\text { Visual Communication } \\
\text { (Various Sign Languages, etc.) }\end{array}$ & $\begin{array}{l}\text { Private and } \\
\text { Public Spaces }\end{array}$ \\
\hline $\begin{array}{l}\text { International } \\
\text { Communication }\end{array}$ & $\begin{array}{l}\text { Visual Information Systems, } \\
\text { Visual Language Learning, etc. }\end{array}$ & $\begin{array}{c}\text { Public Spaces; Large-Scale } \\
\text { Organizations, Traffic Networks, etc. }\end{array}$ \\
\hline
\end{tabular}

Settings, finally, can be defined as spatio-temporal domains in which media can be utilized. From a functional point of view, these settings can be split into major societal systems like education, science and technology, culture and so on. From a holistic viewpoint, settings can be attributed to forms of life or to any spatio-temporal specification like households, work-places, public spaces, etc. Otto Neurath's Isotype can be seen, thus, as a visual medium which has been very successfully applied to different settings like education, culture or science. Moreover, Isotype has been created as a weak rule system with a small number of explicit rules and a large number of implicit routines.

Turning more specifically to contemporary visual media, the most important point to be emphasized lies in the rapid proliferation of a large wave of new visual media which are supported by digital information and communication 
technologies. Digital visual media have programs as their underlying units and their general output lies in visual patterns. Table 2 presents an overview of the startling number of new visual media. Moreover, from Table 2 it becomes clear that these broad scope of new visual digital media offers strong support for the claim that the 21st century will become the century of the digital or, alternatively, of the cyber-eye, following the 20th century as the century of the eye (Otto Neurath).

\section{3}

\section{The Limits of Isotype in the Cyber-Age}

In view of the shift to patterns, complexity science and to digital or cyberresearch environments on the one hand and a new wave of digital visual media and settings across society on the other hand it is worthwhile to contemplate the question whether Isotype as a homogeneous picture language should be adapted or accommodated to the new digital environments across science and society. Probably not unexpectedly, the answer is clearly negative. Basically, three groups of reasons can be given why Isotype cannot and should not be revitalized within the current cyber-contexts.

The first group of reasons against a digital version of Isotype is linked to the overwhelming proliferation of new visual digital media across very different functional settings and with highly heterogeneous user-groups. It is not only difficult to imagine that a single visual medium like Isotype can be meaningfully applied across all these different settings and user-groups, it turns out to be impossible that a single visual medium is capable to fill out all new visual niches. Turning to the science domain alone one is confronted with a very large number of different visual media and with widely differing utilization contexts which make it outright impossible to develop a single visual medium to account for all these different utilizations. Thus, Isotype would need to be developed as a family of different visual media, unified sufficiently by family resemblances in design principles across these different media.

While the first set of arguments against a digital Isotype still allows the building of an Isotype family of visual media, the second group of reasons excludes the possibility of such a digital Isotype-family altogether. The second set of reasons has to do with Isotype as a symbol-based visualization instru- 
ment or as a picture language. Neurath was fully aware that Isotype was not a complete language when compared to a linguistic medium. In his visual autobiography Otto Neurath himself remarked that

there are many reasons why Isotype cannot be developed as a 'complete language' without destroying its force and simplicity. Our daily language, even in primitive societies, is to some extent richer than our Isotype representations can be. (Neurath 2010:104)

Nevertheless, a symbol library lies in the core of Isotype and constitutes its differentia specifica. But from Table 2 it becomes rather obvious that many of the new visual media and settings produce only abstract patterns and do not or, in most instances, cannot rely on symbolic arrangements. In fact, the concluding sections of this article will introduce a visual medium for the social sciences under the name of visual data analysis (VDA). Most of the data-transformations in VDA would be impossible if one were to rely on the symbol library simply because many of the usual data dimensions or variables like trust in institutions, life-satisfaction, political attitudes, policy issues, etc. cannot be symbolized in an adequate manner. ${ }^{8}$ Accordingly, one is faced with the following dilemma: Removing or downsizing the importance of the link to the Isotype-library of symbols would change Isotype to something fundamentally different which no longer can be regarded as an accommodation or an adaption, but as a clear break with the Isotype-past. Keeping the link to the Isotype-library of symbols excludes Isotype for most of the current visual media and settings.

The third group of reasons against a digital version of Isotype comes from the limitations and restrictions of the new digital visual media themselves. The high aesthetic surplus value of Isotype-pictures was achieved through an artistic transformation of objects to self-speaking or self-explanatory symbols. This transformation process required time and the final product was very carefully produced as a single and unique piece. The contemporary online-settings for visual media operate with hundreds and more users, distributed globally, who expect instant visual results. Additionally, computer screens and printers make it almost impossible to achieve this aesthetic Isotype-surplus due to inherent limitations in screen or printing resolutions which become particularly evident when using large numbers of small symbols. Finally, Isotype was based on a closed technology where observers were confronted with a pre-given set 
of visual stimuli, carefully prepared and crafted by the Isotype-team. In sharp contrast, contemporary visual media are essentially grounded in open technologies where users are expected to create the visual outputs most suitable for them in a relatively short amount of time of a few seconds only.

Thus, in the brave new cyber-worlds Isotype remains a vital reference point for visualization goals or for a comprehensive listing of potential comparative advantages of visualizations due to two decades of intensive interactions with numerous observers and users. But Isotype would be lost in transformation from its original mode of analogue manufacturing to the current digital production environments.

\section{4}

\section{A Basic Outline of Visual Data Analysis (VDA) and Its Four Main Contexts in the Social Sciences}

Subsequently, a new visual medium will be introduced which has been designed for the social sciences and which belongs to the new components in a digital social science lab. This new visual medium allows and supports a visual online-analysis of societal changes, observed or simulated, in a comparative framework. This new visual medium which has been established under the name of visual data analysis (VDA $)^{9}$ is based on survey or panel data from a varying number of countries. The primary goal of VDA lies in a visual analysis of patterns which are produced by suitable VDA-programs. Over the last years a new VDA-program has been produced which runs under the name of WISDOMIZE and which is currently available online in its version 2.0. ${ }^{10}$

VDA is one of the new media and settings where the Isotype restrictions become very obvious. Usually, the variables in the micro data sets use concepts which fall beyond the reach of the Isotype-library. Instances like, for example, life satisfaction, trust in institutions, work flexibility, or values do not have counterparts in the Isotype symbol library. Additionally, the European context for VDA requires a large compilation of different countries on a single screen which makes it almost impossible to use any type of symbols because the available space for a larger quantity of symbols is much too small.

Visual data analysis can be undertaken within four different data contexts which can be specified with the help of two independent dimensions. The first dimension is time and can be divided into single points in time or into multiple 


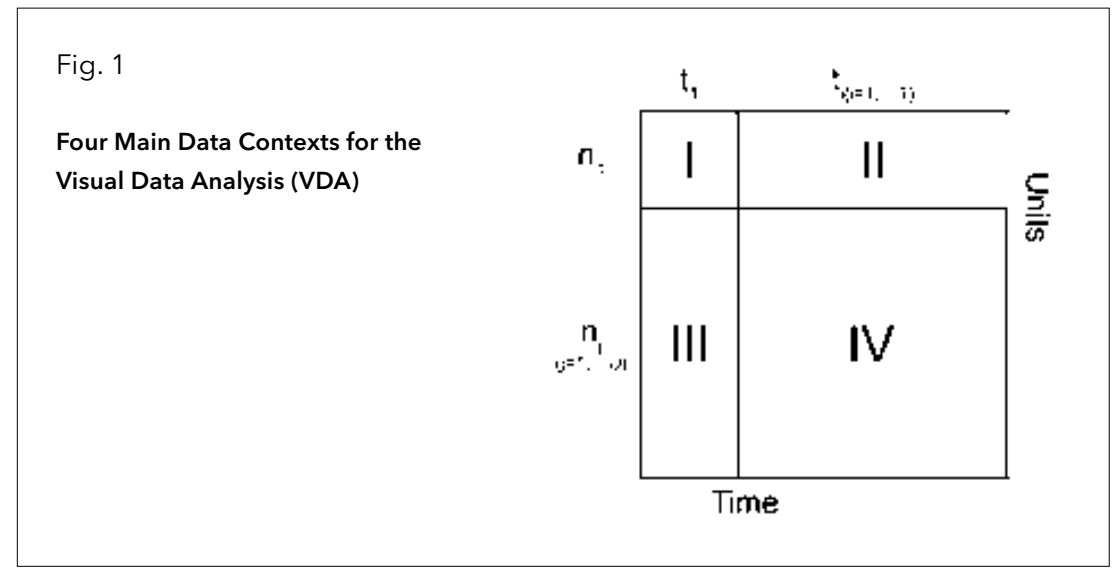

time points. The second dimension can be described as the unit of analysis and can be divided into single units or into multiple units. Units can refer to regions, populations or to both regions and populations. Figure 1 exhibits the four main data contexts for VDA.

With the help of Figure 1 the four different data contexts can be described in a more detailed manner.

- The first context is focused on a single unit $u$ for a single point in time t. In order to become comparative one needs at least a small number of dimensions or variables which are to be compared within this single case-context.

- The second data context is still restricted to a single unit, but uses at least two points of observation $t_{i}(i=1,2, \ldots T)$. Thus, the second context is the most elementary instance for a comparative study of changes.

- The third data context uses at least two different units uj $(j=1,2, \ldots, U)$, but is restricted to a single point in time t. The third context may be seen as the paradigmatic case for comparative analysis.

- Finally, the fourth data context comprises at least two units and two points of observation. The fourth context becomes the most complex one for comparative analyses with $\mathrm{t}_{\mathrm{i}} \times \mathrm{u}_{\mathrm{j}}$ data sets. 
These four data contexts can be used for various forms of pattern recognitions. In principle one can distinguish between two main types or groups of patterns which exhibit important attributes of a data set. These two main groups can be divided into elementary patterns like extreme values, variances ort deviations from the main value and into complex patterns like similarities, coherences or distances.

\section{5}

\section{Patterns and Prototypes within the Visual Data Analysis}

With respect to the two groups of patterns for the different data contexts each group contains a small number of specific patterns. In sum, one can differentiate currently between three elementary or simple patterns and four complex patterns which, in combination, constitute the field of visual data analysis. However, each of these elementary or complex patterns is able to address specific questions and to provide an open and observer-dependent amount of visual answers.

With respect to the group of elementary patterns one can list the following three main instances:

- Extreme values: Patterns for a quick recognition of extreme values and outliers in a given data-set. In this area a number of variables or variable groups as well as of units can be selected and the extreme values of this data set become visualized.

- Deviations from an average or a reference value: Patterns for a rapid insight into higher and lower than average concentrations or, alternatively, into lower and higher formations for a given reference value. Once again, a number of variables or variable groups as well as of units have to be chosen by the user and an average or reference value has to be specified.

- Variance: Patters for a fast identification of the statistical spread in a given data set. These visualizations are mainly, but not exclusively based on scatter plots which have become the main field of visual analysis for variance features. 
The group of complex visual data analyses comprises at present time four different patterns:

- Similarities: Patterns for a quick detection of grades of similarities or dissimilarities between sub-populations in a data set. In this instance $\mathrm{n}$ dimensions or variables must be selected and at least two sub-populations $\mathrm{n}\left(\mathrm{s}_{\mathrm{i}}\right)$ for each unit must be specified.

- Coherence: Patterns for a rapid cognition of interrelations between several data groups. Here one has to select at least two dimensions, but preferably two data groups with $\mathrm{n}$ and o dimensions which can be visually analyzed for their visual positive or negative correlations.

- Clustering: Patterns for a fast identification of groups or types in a data set. In this case, one needs $\mathrm{n}$ dimensions and $\mathrm{u}$ different units in order to find groups or clusters in a given data set. Usually one is capable of selecting two, three or more visual clusters within a given $\mathrm{n} x \mathrm{u}$ dataset.
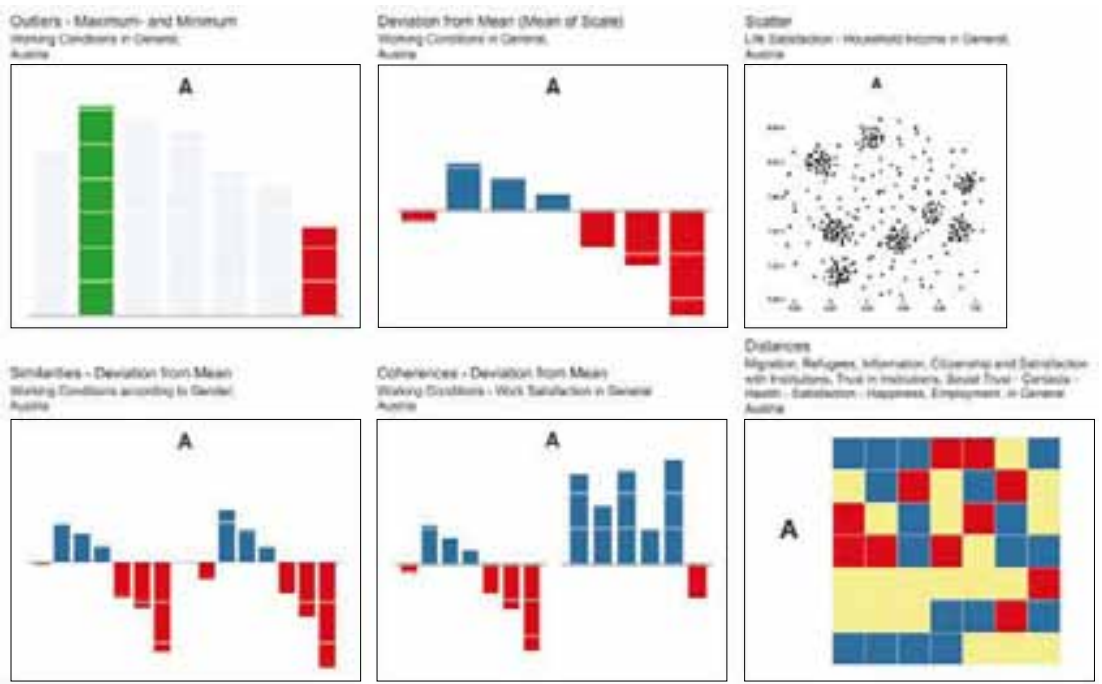

Fig. 2 Six Visual Fields of Analysis for Data Context I (Single Point in Time, Single Unit) 
- Distances: Patterns used for the quick detection of multidimensional distances across relatively large sets of dimensions. Here one needs d different domains within a given data set where each domain contains preferably a constant number of dimensions.

The gallery of patterns in Figure 2 exhibits six cases of visual data analysis within the first data context, namely for a single time point and a single unit. The data come from the European Social Survey (ESS) which can be considered as the European best practice for comparative data production. ${ }^{11}$

Aside from data contexts and elementary or complex patterns one can distinguish between different visual prototypes which visualize a given data set in a specific manner so that it can provide visual answers for specific research questions. From Figure 2 one can see that visual prototypes can be classified with labels like an extreme value-prototype, a deviation-prototype (deviations from a mean or a reference value) or as the data-square or data rectangleprototype. In general, each prototype can be used for one or more elementary or complex patterns and each elementary or complex pattern comprises one or more visual prototypes.

Table 3 lists the three basic components for VDA, namely data contexts, patterns and prototypes.

Table 3 Basic Components of Visual Data Analysis

\begin{tabular}{c|c|c}
\hline $\begin{array}{c}\text { Data: } \\
\text { Elementary and } \\
\text { Complex Data Contexts }\end{array}$ & $\begin{array}{c}\text { Patterns: } \\
\text { Elementary and } \\
\text { Complex Patterns }\end{array}$ & $\begin{array}{c}\text { Prototypes: } \\
\text { Elementary and Complex } \\
\text { Pattern Generators }\end{array}$ \\
\hline $\begin{array}{c}\text { Single Unit, } \\
\text { Single Point in Time }\end{array}$ & $\begin{array}{c}\text { Exteme Values } \\
\text { Deviations from Mean or } \\
\text { Reference Value }\end{array}$ & $\begin{array}{c}\text { A Small Set of Pattern } \\
\text { Generators for One or More } \\
\text { Elementary or } \\
\text { Complex Patterns }\end{array}$ \\
$\begin{array}{c}\text { Single Unit, } \\
\text { Multiple Points in Time }\end{array}$ & Variances \\
Multiple Units, & Similarities \\
Single Point in Time & Coherence & \\
Multiple Units, & Clustering & \\
Multiple Points in Time & Distances & \\
\hline
\end{tabular}




\section{6}

\section{Complex Visual Data Analysis of European Data}

In this section two examples for a complex visual data analysis will be provided and analyzed in some detail. The data come, once again, from the European Social Survey (ESS) and the pattern to be studied visually has been labeled as coherence-analysis. With respect to the data, two different domains have been selected, namely trust in five different institutions, namely the national parliament, the legal system, police, politicians and political parties. The

\section{Context I}

Visual Coharences - Deviation from Mean Trust in Five instupiens / Socisi Cache otgosiness. UA Satistacton, Hath and Four Dinensions for Scasi Caplan? tor Austa

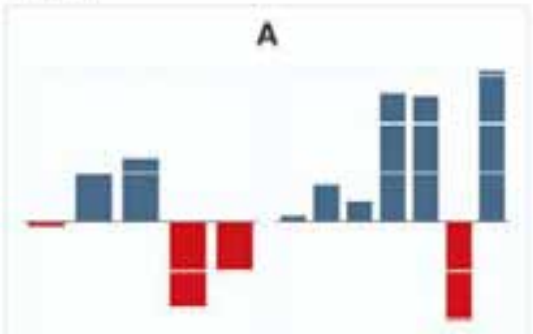

\section{Context ill}

Visual Coherences - Deviation from Mean

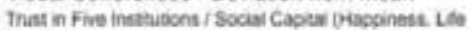

Satistaction, Hinater and Four Dimentiona for Social Capitat 500 Euroes

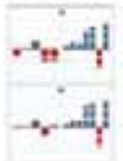

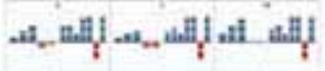

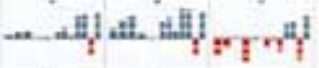

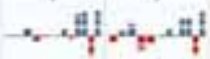

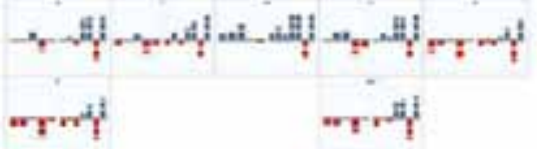

\section{Context II \\ Visual Coherences - Changes, Two Points in Time Trust in Fwe huthosons / Sociei Cachal Gapoiness. $t$ a Sabsticaion, Health and Four Dimensioms for Sosai Captail for Austria}

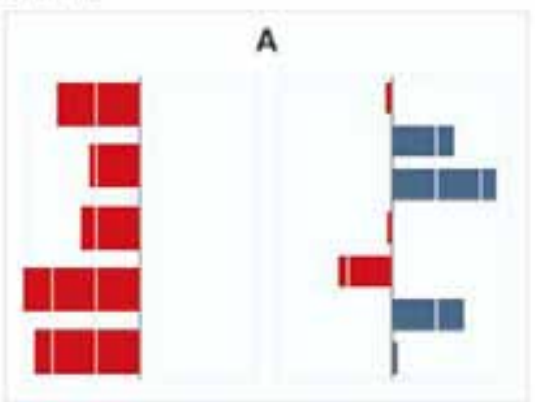

\section{Context iv}

Visual Coherences - Changes, Two Points in Time Thast in Five hotedoons $f$ Sociai Cagtar Hapoinest. Lite Satatuction, lleath and four Direncions for Sociai Captat) sor Eumper
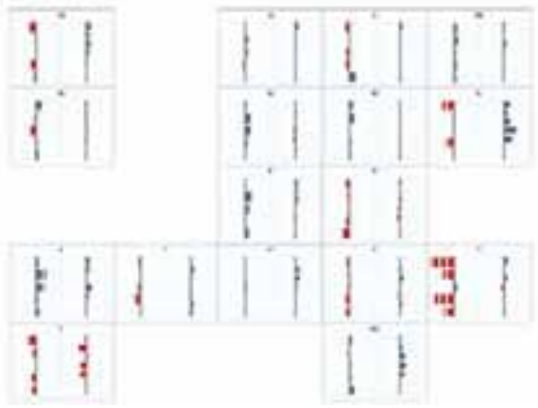

Fig. 3 Visual Coherence-Analyses in Four Data Contexts 
second domain falls under the heading of social capital, including happiness, life satisfaction, health and four specific dimensions for social capital. Figure 3 provides an overview of visual coherence analyses within the four different data contexts where the third and the fourth data context fall under the heading of complex visual data analysis.

As can be easily seen from Figure 3, these patterns provide visual answers to different research questions with respect to underlying coherences between the domain of trust in institutions on the one hand and social capital, broadly understood, on the other hand.

- The first data context provides answers for the coherence between two data groups within a single unit, in this case Austria. Here a competent observer is able to find out whether one can identify a coherent pattern between the two data groups within a single country, in this case in Austria. Obviously, for Austria the coherence between trust in institutions and social capital is weak at best.

- The second data context gives visual clues on dynamic coherences and on answering the question whether two groups of dimensions exhibit a coherent or incoherent dynamic pattern. Clearly from Figure 3 one can see that in the Austrian case no dynamic coherence can be identified and both data groups show a very different dynamical pattern.

- The third data context looks for coherences at the European level for a single point in time. Here one can observe a weak coherence between these two domains across Europe. Countries which are strong in trust in institutions turn out to be strong in social capital as well, although one can find several exceptions to this general pattern.

- Finally, the fourth data context provides visual answers for dynamic coherences at the European level. Generally, one can see that no dynamic coherences can be identified because in many instances positive changes in one domain are accompanied by negative changes in the other domain and vice versa.

Finally, Figure 4 exhibits a gallery of visual patterns for assessing multidimensional socio-economic distances in Austria (data contexts I \& II) and in 
Context 1

Visual Distances - One Point in Time

Serven ESS-Dotnaine: Mgrason Policies (1), Asylum, Policies (2) Meda Utlizason (3) Pancicasion and Catening (a). Trug in

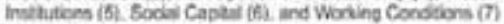
is Austina

A

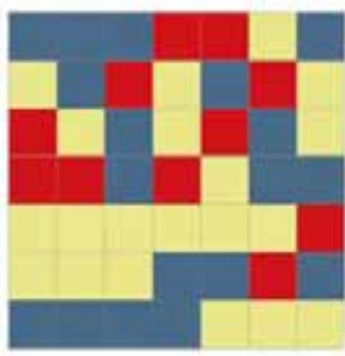

\section{Context III}

Visual Distances - One Point in Time

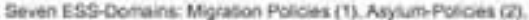
Meda Ustzasion (3i. Pariciostion and Cizenshis (4). Thast in

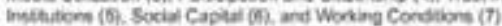
for Eumpe
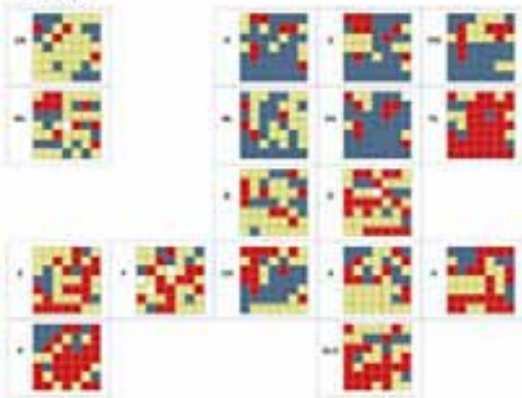

\section{Context if}

Visual Distances - Changes. Two Points in Time

Seven ESS-Domaink Moratios Polcies (1). Asyhan-Potices (2).

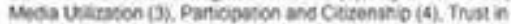
insthutions (S), Bocial Capitat (5), and Woring Condtions (7) Nor Austa

A

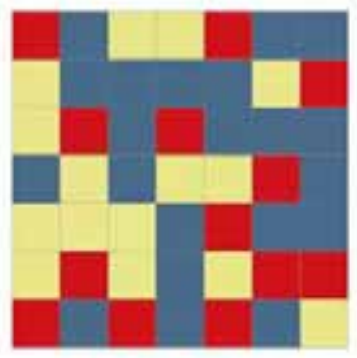

\section{Context IV}

Visual Distances - Changes. Two Points in Time Seven ESS-Domains Mograton Polloits (1). Alykum-Polces (7). Madis Veilzation (3). Parieiprion and Casonshig (4). Thust in

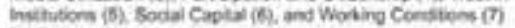
loe Funcoe
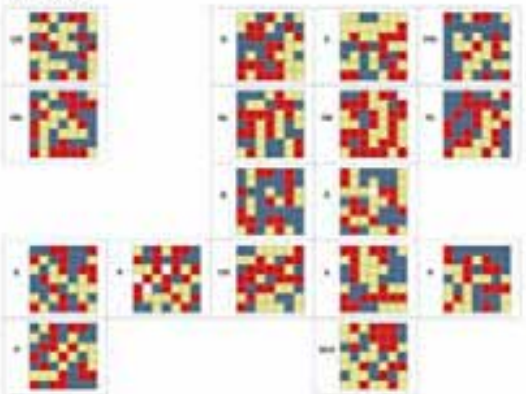

Fig. 4 Visual Distance-Analyses in Four Data Contexts

Europe (data contexts III and IV). The data set comes, once again, from the European Social Survey. This time, seven domains, namely migration policies (1), asylum-policies (2), media utilization (3), participation and citizenship (4), trust in institutions (5), social capital (6), and working conditions (7) have been selected and seven independent dimensions have been selected for each of these domains. Finally, for each of the 7 dimensions x 7 domains the coloring was undertaken in a distribution-dependent way. Take trust in parliament as one of the 49 dimensions used in Figure 4, then the countries which fall 
under the upper third of the distribution were colored in blue, countries in the middle third with ocher and countries in the lower third with red. In this way, each of the 7 domains $x 7$ dimensions in each regional unit was colored either in blue, ocher or red. Consequently, countries with predominantly blue (red) colors are positioned in the upper (lower) third of the European distribution in most of the 49 dimensions. Multidimensional socio-economic distances across Europe can be identified visually by finding countries or regions with mostly blue colors on the one hand and mostly red colors on the other hand. For the third data context in Figure 4 one can see, for example, that Denmark and Poland are the countries with the biggest socio-economic differences across the $7 \times 7$ dimensions. More specifically, the four data context offer visual clues for the following set of research questions.

- Within the first data context an observer gets visual patterns with respect to socio-economic distances between several domains in a single country, namely in Austria. Here a competent researcher is able to find out visually which of the ESS-domains differ most within Austria. As it turns out, the fifth domain (trust in institutions) and the seventh domain (working conditions) exhibit the biggest differences within Austria.

- The second data context offers visual clues on the dynamics of these seven domains and, thus, on the socio-economic distances with respect to the changes in these seven domains. The second data context in Figure 4 shows for example that the second and the sixth domain exhibit the biggest differences within Austria.

- The third data context looks for socio-economic distances across Europe in a highly multi-dimensional context. Observing the third data context more closely one will recognize, for example, that Scandinavia shows very big socio-economic differences to Eastern or South-Western Europe.

- Finally, the fourth data context offers visual patterns for dynamic distances at the European level. This time it remains a task for the reader or observer to identify socio-economic distances with respect to the changes in the seven domains.

With Figures 3 and 4 the preliminary overview on a new visual medium for visual data analysis in the social sciences has come to an end. It should be emphasized that VDA offers a quick detection of characteristic features especially in large-scale European or global data sets. Moreover, VDA can be 
combined with traditional statistical analyses or with qualitative data analyses. In this way, visual methods like VDA close the ensemble of social science methods to a closed triad.

\section{7 \\ Towards Worlds of Visual Media and Visual Settings}

Otto Neurath as a fervent optimist with respect to new technologies would find himself today in local and global contexts which are characterized by a striking discrepancy between an enormous proliferation of new visual media and the absence of high quality visual designs especially suited for these different settings. In all probability, Neurath would explore these different visual media and settings and would produce innovative visual solutions which would be situated well beyond the classical Isotype-approach.

Isotype as a unified symbol language and as a visual medium across different settings in science or society is definitely dead within today's cyberenvironments. But several of the general design principles still live on and it would be a fascinating second-order task to see whether today's worlds of visual media adhere to these general standards and principles on the one hand and are able to fulfill the comparative advantages inherent in visualization. In this sense, Neurath's Isotype remains a vital and critical reference point for the current visual cyber-environments as they have been developed so far and for the visual media and settings still to come.

\section{Notes}

1 On Neurath's Isotype, see Neurath, 1991, 2010 or Müller, 1991a,b.

2 On this point see especially Müller, 1991b.

3 On the distinction between Science I and Science II, see Hollingsworth/Müller, 2008 or Müller/Toš, 2011. For a wider discussion of this distinction, see Boyer, 2008, Mayntz, 2008, Nowotny, 2008 or Sornette, 2008.

4 On the notion of epistemic cultures see especially Knorr-Cetina, 1999.

5 Laboratories in a very general way can be seen as the spatio-temporal settings in which epistemic cultures manifest themselves. See especially Latour/Woolgar, 1979 or Knorr-Cetina, 1984. 
6 Otto Neurath would have been a keen observer of this process because already in the early 1940s he proposed a so-called Gelehrtenbehavioristik which was characterized by him in the following way, taking sociology as reference point: 'Sociologists deal, among other things, with tools and tales, with the language of magic, theology, jurisprudence, economics, and pedagogics; but also with the language used by the sociologists themselves, with their statements and their habits, i. e. with the behavioristics of sociologists [...] We have fine questionnaires as far as preliterate tribes are concerned but hardly any when we try to ask sociologists how they themselves behave in arguing and writing. Since sociological predictions are directly connected with actions which create what has been predicted, the difficulty is very understandable. More than in other sciences, taboos and old folklore come into the picture when human actions are under consideration.' (Neurath 1970: 42 p.)

7 For a contemporary summary, see Bentele/Brosius/Jarren, 2003, Faßler/Halbach, 1998, Grau, 2007, Grau/Keil, 2005, Hickethier, 2003, Leschke, 2003, Liebrand/ Schneider/Bohnenkamp/Frahm, 2005, Ludes, 2003, Lüsebrink, 2003, Lüsebrink or Rusch, 2002.

8 As an Isotype-transformer one is usually faced with the following dilemma. Even for seemingly empirically observable dimensions in social science data sets like political attitudes or social capital one can either invent new symbols which, however, are no longer self-explanatory and have to be described for observers separately or one abandons the search for appropriate symbols altogether and loses, thus, the power of visual arrangements. In general, even moderately theoretical terms are not only difficult, but outright impossible to visualize in a self-evident manner. (For a detailed discussion, see Müller, 1991a)

9 On visual data analysis (VDA) see, for example, Müller/Reautschnig, 2010.

10 For a deeper understanding, visit the wisdom homepage under www.wisdom.at and look under the category of visualization in order to proceed to WISDOMIZE 2.0 .

11 On the European Social Survey (ESS), see, for example, Jowell et al. (2007) or Toš/ Müller et al., 2009.

\section{Literature}

Bentele, G., Brosius, H.B., Jarren, O. (2003) (eds.), Öffentliche Kommunikation. Handbuch Kommunikations- und Medienwissenschaft. Wiesbaden: Westdeutscher Verlag. Boyer, R. (2008), 'The Quest for Theoretical Foundations of Socio-Economics: 
Epistemology, Methodology or Ontology?', in: 'Discussion Forum: On Rogers Hollingsworth and Karl H. Müller "Transforming Socio-Economics with a New Epistemology",, in: Socio-Economic Review 6, 733-746.

Breckner, R. (2008), 'Bildwelten - Soziale Welten. Zur Interpretation von Bildern und Fotografien', in: Online-Beitrag zu Workshop \& Workshow vom 23./24. 11.2007, www.univie.ac.at/visuellesoziologie.

Eco, U. (2002), Einführung in die Semiotik, neunte Auflage. München: UTB.

Faßler, M., Halbach, W.R. (1998) (eds.), Geschichte der Medien. München: Fink.

Grau, O. (2007) (ed.), MediaArtHistories. Cambridge: MIT-Press.

Grau, O., Keil, A. (2005) (eds.), Mediale Emotionen. Zur Lenkung von Gefühlen durch Bild und Sound. Frankfurt: Fischer.

Hayek, F:A.v. (1967), Studies in Philosophy, Politics and Economics. London: Routledge \& Kegan Paul, 22-42.

Hayek, F.A.v. (1972), Die Theorie komplexer Phänomene. Tübingen: J. G. B. Mohr (Paul Siebeck).

Hayek, F: A. v. (1996), 'Die Theorie komplexer Phänomene', in ders.: Die Anmaßung von Wissen. Neue Freiburger Studien. Tübingen: Mohr Siebeck, 281-306.

Hickethier K. (2003), Einführung in die Medienwissenschaft. Stuttgart: Metzler.

Hofstadter, D. R. (1997), Le Ton Beau de Marot. In Praise of the Music of Language. New York: Basic Books.

Hollingsworth, J. R., Müller, K.H. (2008), 'Transforming Socio-Economics with a New Epistemology', in: Socio-Economic Review 3 (6), 395-426

Jowell, R., Roberts, C., Fitzgerald, R., Gillian, E. (2007) (eds.), Measuring Attitudes CrossNationally: Lessons from the European Social Survey. London: Sage Publications.

Knorr-Getina, K. (1984), Die Fabrikation von Erkenntnis. Zur Anthropologie der Naturwissenschaft. Frankfurt am Main: Suhrkamp.

Knorr-Cetina, K. (1999), Epistemic Cultures. How the Sciences Make Knowledge. Cambridge: Harvard Univ. Press.

Latour, B., Woolgar, S. (1979), Laboratory Life: The Social Construction of Scientific Facts. Beverly Hills: Sage Publications.

Leschke, R. (2003), Einführung in die Medientheorie. München: Fink.

Liebrand, C., Schneider, I., Bohnenkamp, B., Frahm, L. (2005) (eds.), Einführung in die Medienkulturwissenschaft. Münster: LIT.

Ludes, P. (2003), Einführung in die Medienwissenschaft - Entwicklungen und Theorien, second edition. Berlin: Schmidt 2003.

Lüsebrink, H.-J. (2004), Französische Kultur- und Medienwissenschaft. Eine Einführung. Tübingen: Narr. 
Mayntz, R. (2008), 'Networks and Self-Organization: Dissecting the Model of "Complex Networks", in: 'Discussion Forum: On Rogers Hollingsworth and Karl H. Müller "Transforming Socio-Economics with a New Epistemology", in: SocioEconomic Review 6, 750-754.

Müller, K. H. (1991a), Symbole - Statistik - Computer - Design. Otto Neuraths Bildpädagogik im Computerzeitalter. Wien:Hölder-Pichler-Tempsky

Müller, K. H. (1991b), 'Neurath's Theory of Pictorial-Statistical Representation', in: Thomas Uebel (Hrsg.), Rediscovering the Forgotten Vienna Circle. Austrian Studies on Otto Neurath and the Vienna Circle. Dordrecht: Kluwer Academic Publishers, 223-251.

Müller, K. H., Reautschnig, A. (2010), 'Die visuelle Datenanalyse (VDA) in der vergleichenden sozialwissenschaftlichen Forschung', in: T. Hug, A. Kriwak (eds.), Visuelle Kompetenz. Beiträge des interfakultären Forums Innsbruck Media Studies. Innsbruck: Innsbruck University Press, 236-250.

Neurath, O. (1970), 'Foundations of the Social Sciences', in: Neurath, O., Carnap, R., Morris, C. (eds.), Foundations of the Unity of Science. Toward an International Encyclopedia of Unified Sciences, Vol. 2. Chicago and London: The University of Chicago Press.

Neurath, O. (1991), Gesammelte bildpädagogische Schriften. Wien: Hölder Pichler Tempsky.

Neurath, O. (2010), From Hieroglyphics to Isotype. A Visual Autobiography. London: Hyphen Press.

Nowotny, H. (2008), 'Bargaining, Not Borrowing: On Problem Choice and Problem Space', in: 'Discussion Forum: On Rogers Hollingsworth and Karl H. Müller "Transforming Socio-Economics with a New Epistemology", in: Socio-Economic Review 6, 754-759.

Sornette, D. (2008), 'Interdisciplinarity in Socio-Economics, Mathematical Analysis and the Predictability of Complex Systems', in: 'Discussion Forum: On Rogers Hollingsworth and Karl H. Müller "Transforming Socio-Economics with a New Epistemology",, in: Socio-Economic Review 6, 759-770.

Rusch, G. (2002) (ed.), Einführung in die Medienwissenschaft. Wiesbaden: Westdeutscher Verlag.

Toš, N. Müller, K. H. et al. (2009), Three Roads to Comparative Research: Analytical, Visual, Morphological. Wien: edition echoraum. 